\title{
A trick for performing PEG-J more quickly
}

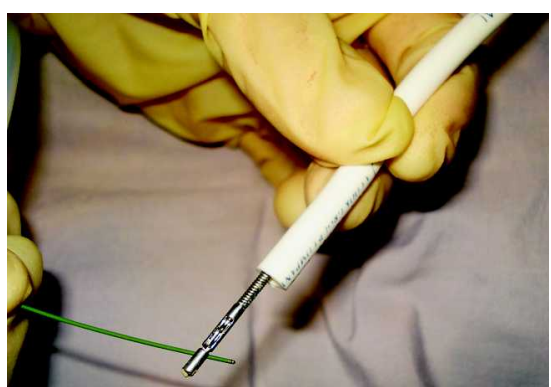

Fig. 1 The guide wire is easily grabbed by the biopsy forceps, which emerges from the gastrostomy tube.

As the aged population continues to increase, percutaneous endoscopic gastrostomy-jejunostomy (PEG-J) is being increasingly performed throughout the world. Many endoscopists are not fully satisfied with the technique of insertion, so there have been attempts reported in the English literature to modify the classical method [1 -4].

In the classical method, the endoscopist should catch the guide wire inserted through the gastrostomy tube into the stomach using a biopsy forceps. Sometimes catching the guide wire may be difficult, especially if the abdominal breathing of the patient is prominent or if there are powerful contractions in the stomach wall. Air leaking out through the gastrostomy tube making the luminal distention inadequate is another problem for the endoscopist. Last but not the least, the tip of the forceps inserted through the endoscope into the stomach may come out in such a way that the guide wire may be parallel to the open mouth of the forceps. For an easier procedure, the guide wire should also be caught close to the tip, and this is another problem for the endoscopist.

To solve these problems we found a simple solution - a trick. The biopsy forceps is inserted through the instrument channel of the endoscope, into the stomach lumen, and then into the gastrostomy tube and out of the tube and patient's body. Then under direct eye and hand control, it is very easy to grab the guide wire outside the gastrostomy tube quickly and exactly close to its tip ( $\bullet$ Fig. 1 and 2).

We have performed this new method in five cases, and performed classical PEG-J in five age- and sex-matched controls.

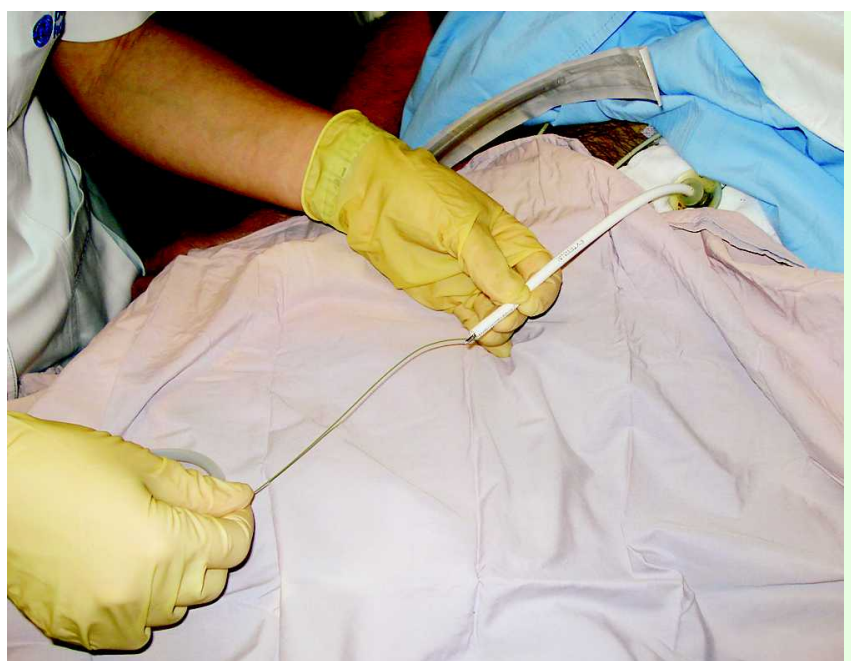

Fig. 2 The guide wire is easily grabbed by the biopsy forceps, which emerges from the gastrostomy tube.

Then we compared the procedure times. The procedure time was, on average, 80 seconds less with the new method. We think our new method saves time and makes PEG-J easier.

Endoscopy_UCTN_Code_TTT_1AO_2AK

\section{G. Oksuzoglu, T. Kav, Y. Ates, S. Bagci}

Department of Gastroenterology,

Bayýndýr Hospital, Ankara, Turkey

\section{References}

1 Sibille A, Glorieux D, Fauville JP et al. An easier method for percutaneous endoscopic gastrojejunostomy tube placement. Gastrointest Endosc 1998; 48: 514-517

2 DeLegge MH, Patrick P, Gibbs R. Percutaneous endoscopic gastrojejunostomy with a tapered tip, nonweighted jejunal feeding tube: improved placement success. Am J Gastroenterol 1996; 91: 1130-1134

3 Boujaoude J, Hobeika E, Nasnas $R$ et al. Percutaneous endoscopic gastroduodenostomy: modified technique. Gastroenterol Clin Biol 2005; 29: 505-507

4 Melvin W, Fernandez JD. Percutaneous endoscopic transgastric jejunostomy: a new approach. Am Surg 2005; 71: 216-218
Bibliography

DOI $10.1055 / \mathrm{s}-2008-1077336$

Endoscopy 2008; 40: E184

(c) Georg Thieme Verlag KG Stuttgart · New York . ISSN 0013-726X

\section{Corresponding author}

\section{G. Oksuzoglu, MD}

Department of Gastroenterology

Bayýndýr Hospital

Eski Ehir Yolu

Sogutozu

Ankara 06520

Turkey

Fax: +90-312-2844277

guroloksuzoglu@hotmail.com 